\title{
Типичные сферы конституционного взаимодействия палат бикамеральных парламентов стран Африки
}

\author{
Мархгейм М.В., Безуглая А. А. \\ Белгородский государственный национальный исследовательский университет, \\ Россия, 308015, г. Белгород, ул. Победы, 85 \\ E-mail:markheim@bsu.edu.ru; minasyan@bsu.edu.ru
}

\begin{abstract}
Аннотация. По своей значимости и уровню формализации взаимодействие публичных конституционных субъектов претендует на статус конституционного принципа, который наиболее последовательно реализуется в бикамеральных парламентах. Конституционное взаимодействие палат парламентов исследовалось ранее на примерах фокусных групп стран СНГ, Азии, Европы. Выявленные закономерности составили матрицу для проведения аналогичного анализа по странам Африки. Авторами сделан акцент на выявлении универсальных (типичных) сфер взаимодействия палат парламентов. Исследование показало, что в числе таковых - законодательная сфера, предполагающая консолидированное участие палат в разработке и принятии законодательства, проведении совместных заседаний по различным поводам; контрольная сфера, представленная тремя сегментами: кадрово-контрольным (связан с отрешением от должности главы государства и премьер-министра), организационно-контрольным (касается участия палат в формировании совместных комиссий и органов власти) и финансово-контрольным (затрагивает вопросы принятия палатами парламента государственного бюджета).
\end{abstract}

Ключевые слова: конституция, взаимодействие палат парламента, универсальные сферы взаимодействия палат парламентов, южноафриканский регион.

Благодарности: исследование проведено при финансовой поддержке Гранта Президента РФ, номер проекта - МК-1377.2020.6, тема проекта «Интегральная роль взаимодействия палат парламента в обеспечении конституционного права на свободу слова», соглашение № 075-15-2020411 от 16.03 .2020

Для цитирования: Мархгейм М.В., Безуглая А.А. 2021. Типичные сферы конституционного взаимодействия палат бикамеральных парламентов стран Африки. NOMOTHETIKА: Философия. Социология. Право, 46 (2): 368-375. DOI 10.52575/2712-746X-2021-46-2-368-375

\section{Typical areas of constitutional interaction between the Chambers of bicameral parliaments of African countries}

\author{
Marina V. Markheym, Anna A. Bezuglya \\ Belgorod National Research University, \\ 85 Pobeda St, Belgorod, 308015, Russian Federation \\ E-mail: markheim@bsu.edu.ru; minasyan@bsu.edu.ru
}

\begin{abstract}
By its significance and level of formalization, the interaction of public constitutional subjects claims to be a constitutional principle, which is most consistently implemented in bicameral parliaments. The constitutional interaction of the chambers of parliaments was studied earlier on the examples of focus groups of the CIS countries, Asia, and Europe. The identified patterns formed a certain matrix for conducting a similar analysis for African countries. By its significance and level of formalization, interaction claims to be a constitutional principle. This principle is most consistently implemented in bicameral parliaments. The constitutional interaction of the chambers of parliaments was studied earlier on
\end{abstract}


the examples of the CIS countries, Asia, and Europe. The identified patterns formed a certain matrix for conducting a similar analysis for African countries. This article presents the results of a comparative legal analysis of the constitutional acts of African countries regarding the consolidation in them of the spheres of interaction between the chambers of parliaments. The study showed that among the universal spheres of interaction between the chambers of parliament is the legislative sphere, which presupposes the consolidated participation of the chambers in the development and adoption of legislation; the control sphere, represented by a set of three segments: personnel and control (associated with the dismissal of the head of state and prime minister), organizational and control (concerns the participation of chambers in the formation of joint commissions and government bodies) and financial control (concerns the adoption by the chambers of parliament state budget).

Keywords: constitution, interaction of chambers of parliament, typical spheres of interaction of chambers of parliament, South African region.

Acknowledgements: the study was conducted with the financial support of the Grant of the President of the Russian Federation, project number-MK-1377.2020.6, project topic "The integral role of interaction between the Chambers of Parliament in ensuring the constitutional right to freedom of speech", agreement No. 075-15-2020-411 of 16.03.2020.

For citation: Markhgeym M.V., Bezuglya A.A. 2021. Typical areas of constitutional interaction between the Chambers of bicameral parliaments of African countries. NOMOTHETIKA: Philosophy. Sociology. Right, 46 (2): 368-375 (in Russian). DOI 10.52575/2712-746X-2021-46-2-368-375

\section{Введение}

Взаимодействие публичных конституционных субъектов является верным способом обеспечения единства публичного пространства государства и устойчивости государственного механизма. По своей значимости и уровню формализации взаимодействие претендует на статус конституционного принципа [Мархгейм, 2018: 56]. Данный принцип наиболее последовательно реализуется в бикамеральных парламентах. Конституционное взаимодействие палат парламентов исследовалось ранее на примерах иных фокусных групп государств, как то: страны СНГ [Мархгейм, Безуглая, 2020], Азии [Стус и др., 2019], Европы [Полухин, Минасян, 2018]. Выявленные закономерности составили определенную матрицу для проведения аналогичного анализа по странам Африки.

Выявление конституционных форм взаимодействия палат парламента обусловлено, в первую очередь, тем, что парламент выступает в качестве единого органа, императивно уполномоченного не только принимать законодательные акты от имени государства, но и участвовать в реализации различных функций последнего (контрольной, международной, кадровой, безопасности и др.) Такая конституционная прерогатива парламента детерминирует интерес к его исследованию, особенно в ходе рассмотрения деятельности бикамеральных парламентов, поскольку только благодаря взаимодействию обеих палат реализуется, прежде всего, законодательная власть в государстве. В качестве примера возможно привести положения ст. 35 Конституции Габона [Хабриева, 2018: 593]: «Законодательная власть представлена Парламентом, который состоит из двух палат: Национального собрания и Сената». Аналогичные формулировки содержатся в п (а) ст. 106 Конституции Эсватини (Свазиленда) - «высшая законодательная власть в Свазиленде принадлежит Королю-в-Парламенте», в ст. 100 Конституции Демократической республики Конго [Хабриева, 2018: 676]: «Законодательная власть состоит из Парламента, состоящего из двух палат: Национального Собрания и Сената». Подобные примеры нашли отражение и в иных конституционных актах: ст. 147 Конституции Бурунди, ст. 50 Конституции Зимбабве, ст. 93 Конституции Кении, ст. 64 Конституции Ранды и др.

Весьма оригинальными (в контексте конституционного интерпретирования законодательной власти) являются положения ст. 44 Конституции Намибии: «Законодательная 
власть в Намибии принадлежит Национальному Собранию». Следует отметить, что наряду с Национальным Собранием в парламент входит и вторая палата - Национальный Совет (ч. 2 (а) ст. 146 Конституции Намибии). Подчеркнем, что такой подход по сравнению с иными бикамеральными парламентами государств, например, Европы и Азии, является исключением, нежели правилом [Никонова, Минасян, 2017; Dzybova et al, 2018; Minasyan, 2019].

\section{Законодательная сфера взаимодействия палат бикамеральных парламентов}

Проведенный анализ 20 конституций стран Африки, имеющих бикамеральный парламент, позволил сформулировать вывод о наличии универсальных (типичных) сфер взаимодействия палат парламентов.

Наряду с иными государствами [Минасян, Никонова, 2016; Минасян, Никонова, 2016; Полухин, Минасян, 2018; Стус и др., 2019] к числу универсальных сфер взаимодействия в странах Африки ожидаемо относится законодательная сфера. Согласно конституционным положениям ст. 78 Конституции Лесото законопроект принимается посредством его прохождения «через обе палаты Парламента». Уточним, что в названном конституционном акте закреплено внесение законопроекта только в нижнюю палату парламента Национальное Собрание.

Так, в ст. 36 Конституции Габона закреплено право Парламента (исходя из контекста конституционного акта, речь идет о двух палатах) «голосовать за законы». Отмечено, что «Любой законопроект... последовательно рассматривается в обеих палатах Парламента». Следует отметить, что конституционные роли относительно внесения законопроекта в конкретную палату не установлены. Такой подход законодателя разделяют и иные рассматриваемые парламенты (например, ст. 130 Конституции Демократической Республики Конго, ст. 147 Конституции Конго). Исключения составляют только финансовые законопроекты (ст. 54 Конституции Габона).

Конституция Эсватини в ст. 107 закрепляет положения о том, что законопроекты принимаются обеими палатами Парламента. При этом отмечены случаи, когда законопроект должен быть принят исключительно на совместном заседании (ст. ст. 115 (3), 116 (1), 117). Уточним, что конституировано право направления законопроекта в обе палаты парламента, за исключением финансовых и иных законопроектов, затрагивающих вопросы статуса, полномочий, назначения высших органов государства, национальных земель, обычаев и др. (ст. 110 и ст. 115 (6) Конституции Эсватини). Следует отметить, что палаты Парламента обладают правом принятия поправок к Конституции. Подобные законопроекты должны быть внесены только на совместное заседание палат, где будет решаться вопрос об их принятии или отклонении. Исходя из положений ст. 245 , можно сформулировать вывод о том, что изменения в основной закон этой страны могут быть внесены как путем совместного волеизъявления парламентариев обеих палат парламента, так и посредством вынесения законопроекта на референдум.

Следует заметить, что законотворческие функции парламента затрагивают и систему прав человека. Нетипичными для фокусной группы стран являются полномочия палат парламента в части дополнительной регламентации требований как для лиц - граждан Лесото, так и лиц, претендующих на приобретение гражданства. Так, согласно ст. 42 Конституции Лесото Парламент вправе «установить порядок и правила лишения гражданства Лесото любого лица», за исключением двух категорий: граждан Лесото в силу рождения и граждан «Лесото по происхождению, при условии, что, будучи лишенными гражданства, эти лица станут лицами без гражданства». 
В качестве продуктивного, на наш взгляд, отличия от иных рассматриваемых конституционных актов, Конституция ЮАР в качестве обязанности палат парламента закрепляет создание комитета «по общим правилам процедуры для разработки регламента и правил совместной работы Собрания и Совета» (ст. 45). Помимо прочего, палаты создают совместные комитеты для «ежегодного пересмотра Конституции», «по вопросам общего регламента» и др. Подчеркнем, что формирование перечисленных выше комитетов, как представляется, направлено на повышение эффективности работы парламентариев. Дополнительным аргументом в пользу такого вывода является обязательное создание согласительной комиссии, которая формируется в случае отклонения палатой принятого законопроекта (ст. 76). Согласительная комиссия действует в течение 30 дней с момента отклонения законопроекта одной из палат и состоит из парламентариев обеих палат парламента (ст. 78). Конституировано, что «согласительная комиссия одобряет вариант законопроекта или выносит решение по вопросу, если их поддерживают» не менее пяти представителей от каждой палаты парламента. Полагаем, что такое правило отражает не только специфику принятия решений в бикамеральном парламенте, но и подчеркивает общность деятельности палат парламента. Формирование согласительных комиссий конституировано и в ст. 58а Конституции Габона, ст. 113 Демократической Республики Конго, ст. 148 и ст. 150 Конституции Конго.

В ходе исследования было установлено, что законодательная сфера взаимодействия палат парламента выражается в различных формах, например, совместном заседании палат. Анализ данной формы сотрудничества палат рассматриваемой группы государств позволил установить поводы для их проведения, в числе которых:

- церемониальные (участие в процедуре инаугурации главы государства (ст. 12 Конституции Габона, ст. 77 Конституции Конго, ст. 53 Конституции Либерии, ст. ст. 37, 45 Конституции Экваториальной Гвинеи) или членов Конституционного Суда (ст. 90 Конституции Габона)). Полагаем необходимым подчеркнуть, что Конституция Экваториальной Гвинеи закрепляет положение о формировании «Совета Чести» (состоит из членов Бюро палат Парламента, Верховного суда и Конституционного трибунала), необходимого для процедуры инаугурации Президента. Такой подход является нераспространенным в практике конституционной формализации как стран Африки, так и стран европейского и азиатского регионов;

- заслушивание посланий главы государства (ст. 24 Конституции Габона, ч. 3 ст. 119 Конституции Демократической Республики Конго, ст. 94 Конституции Конго);

- участие палат парламента в предъявлении обвинения главе государства (ст. 166 Конституции Демократической Республики Конго, ст. 95 Конституции Конго, ст. 43 Конституции Либерии) и Премьер-Министру (ст. 166 Конституции Демократической Республики Конго); Гвинеи);

- ратификация назначения Вице-президента (ст. 33 Конституции Экваториальной Конго);

- пересмотр Конституции (ч. 1 ст. 119 Конституции Демократической Республики

- одобрение решения главы государства относительно введения чрезвычайного или особого положения (ч. 2 ст. 119 Конституции Демократической Республики Конго, ст. 23 (8) Конституции Лесото, ст. 86 и 88 Конституции Либерии, Приложение Первое Конституции Эсватини, ст. 37 Конституции ЮАР), продления чрезвычайного или осадного положений в стране (ст. 157 Конституции Конго), а также объявления войны (ч. 2 ст. 119 Конституции Демократической Республики Конго и ст. 156 Конституции Конго, «VIII» ст. 32 Конституции Мадагаскара);

- назначение членов соответствующих органов власти (например, членов Конституционного Суда - ст. 158 Конституции Демократической Республики Конго). 


\section{Контрольная сфера взаимодействия палат бикамеральных парламентов}

Типичной сферой сотрудничества палат парламентов исследуемой группы стран является контрольная. Анализ конституционных актов южноафриканских государств с бикамеральным парламентом дал основания для вывода о наличии трех сегментов взаимодействия его палат - кадрово-контрольной, организационно-контрольной и финансово-контрольной.

Первый сегмент реализуется в связи с отрешением от должности главы государства (импичмент), а также в связи с выражением недоверия министрам. Так, согласно положениям ст. 53 Конституции Лесото, палаты парламента на раздельных заседаниях принимают решение о пребывании лица в должности Короля. Данное решение основывается на докладе, полученном от Премьер-министра. Уточним, что конституционно приоритет отдается резолюции Национального Собрания. Король слагает свои полномочия уже в том случае, если такое решение принято одной из палат. Институт импичмента закреплен и в Конституции Намибии. В ст. 29 отмечается, что глава государства может быть отстранен от должности только при наличии постановления, принятого обеими палатами парламента квалифицированным (более $2 / 3$ ) большинством голосов. Заметим, что в ЮАР отстранение Президента от должности (ст. 89) не решается палатами совместно. Это конституционная прерогатива принадлежит Национальному Собранию.

Кадрово-контрольный сегмент также связан с отстранением от должности Премьерминистра. Конституция Эсватини закрепляет, что в случае рассмотрения вопроса об освобождении от должности Премьер-министра глава государства создает комиссию, членами которой являются, в том числе, Спикер Палаты или Председатель Сената (ст. 68 Конституции Эсватини). Отметим также, что конституирована коллективная ответственность Кабинета перед парламентом (ст. 69). Аналогичная формулировка содержится в ст. 88 Конституции Лесото и ст. 92 Конституции ЮАР.

Организационно-контрольный сегмент является разновидностью контрольной сферы взаимодействия палат парламентов. Прежде всего он реализуется в связи с правомпалат создавать совместные постоянно действующие комиссии [Минасян, 2017; Минасян, Никонова, 2017] или комитеты, а также различные органы власти. О создании согласительных комиссий речь велась нами ранее, поэтому полагаем уместным обратиться к анализу иных типов комиссий/комитетов. В ст. 129 Конституции Эсватини закрепляется возможность палат парламента создавать «сессионные комитеты и иные комитеты, необходимые для эффективного осуществления функций палаты». Уточнено, что функциональные полномочия комитетов зависят от Парламента и могут предусматривать также расследование и контроль за деятельностью «министерств и департаментов». Следует отметить, что в странах Центральной Африки предусматривается право палат парламента на формирование смешанной комиссии для взаимодействия с Народным Защитником в (ст. 124 Конституции Экваториальной Гвинеи).

Конституция Лесото в ст. 127 закрепляет за парламентом право «учреждать суды, подчиненные Высокому Суду, военно-полевые суды и трибуналы, и любой подобный суд или трибунал».

Разновидностью организационно-контрольного сегмента является формирование системы местных органов власти палатами парламента. Такие полномочия конституционно адресованы парламентам Лесото и Эсватини (ст. 106 и ст. 218 соответственно). Заметим, что местный (локальный) уровень власти в современных государствах традиционно формируется без участия парламента.

Третьим сегментом контрольной сферы является финансово-контрольная. Она затрагивает, прежде всего, государственный бюджет (ст. 48 Конституции Габона, ст. 126 Демократической Республики Конго, ст. 124 Конституции Конго, ст. 70 Конституции Экваториальной 
Гвинеи), систему налогов и сборов, создание разнообразных внебюджетных фондов и т.д. Следует отметить, что данный сегмент контрольной сферы взаимодействия палат парламентов может быть отнесен и к законодательной сфере, поскольку реализуется в форме принятия законодательного акта (например, ст. 79-80, ст. 111 Конституции Лесото, ст. 77 Конституции Намибии, ст. 110-111 Конституции Эсватини, ст. 73-77 Конституции ЮАР).

\section{Заключение}

Суверенное решение государства о конституировании структуры парламента обусловливает и отражение в основном законе механизмов и сфер взаимодействия его палат. Ранее выявленные закономерности в конституционном закреплении взаимодействия палат парламента стран Азии, Европы, СНГ позволили более предметно проанализировать конституционные подходы тех стран Африки, которые имеют бикамеральный парламент. По итогам анализа выявлены типичные (универсальные) сферы взаимодействия палат парламента.

В качестве базовой сферы взаимодействия палат парламентов указанной группы стран выступает законодательная, реализуемая в форме принятия законов, в том числе финансовых (касаются принятия государственного бюджета), и проведения совместных заседаний по различным поводам.

Универсальной сферой сотрудничества палат парламентов исследуемой группы стран является также контрольная. Анализ конституционных актов указанной группы стран дал основания для вывода, что она представлена совокупностью трех разновидностей: кадрово-контрольной (реализуется в связи с отрешением от должности главы государства и выражением недоверия министрам (Намибия, ЮАР), отстранением от должности Премьерминистра (Эсватини)); организационно-контрольной (осуществляется в связи с правом палат создавать совместные постоянно действующие комиссии и комитеты, а также формировать различные органы власти (Эсватини, Лесото)) и финансово-контрольной (касается установления системы налогов и сборов, государственного бюджета, налоговых льгот и др. (Лесото, Намибия, Эсватини, ЮАР)).

\section{Список источников}

1. Конституции государств Африки и Океании: сборник. Том 3. Южная Африка / отв. ред. Т.Я. Хабриева. 2018. М.: Институт законодательства и сравнительного правоведения при Правительстве Российской Федерации, 992 с.

2. Конституции государств Африки и Океании: сборник. Том 1. Северная и Центральная Африка / отв. ред. Т.Я. Хабриева. 2018. М.: Институт законодательства и сравнительного правоведения при Правительстве Российской Федерации, 927 с.

\section{Список литературы}

1. Мархгейм М.В. 2018. Взаимодействие как конституционный принцип. Наука и образование: хозяйство и экономика; предпринимательство; право и управление, 1 (92): 54-56.

2. Мархгейм М.В., Безуглая А.А. 2020. Конституционно-правовой опыт взаимодействия бикамеральных парламентов стран СНГ в сфере продовольственной безопасности. Социальнополитические науки, Т. 10, 5: 43-49.

3. Минасян А.А. 2017. «Согласительное» взаимодействие палат Федерального Собрания Российской Федерации. Наука и образование: хозяйство и экономика; предпринимательство; право и управление, 2 (81): 88-91.

4. Минасян А.А., Никонова Л.И. 2016. Взаимодействие палат зарубежных парламентов в законодательной сфере. В. кн.: Конституционализация России: проблемы теории и современной практики. Под ред. Мархгейм М.В. Белгород: 86-90.

5. Минасян А.А., Никонова Л.И. 2017. Комитеты и комиссии палат зарубежных парламентов: структурно-функциональная характеристика. В. кн.: Право и государство в современном мире: состояние, проблемы, тенденции развития: материалы IV международной 
научно-теоретической конференции «Мальцевские чтения» памяти заслуженного деятеля науки Российской Федерации, члена-корреспондента РАН, доктора юридических наук, профессора Мальцева Геннадия Васильевича. Белгород, 28 апреля 2017 г. Белгород: 89-93.

6. Минасян А.А., Никонова Л.И. 2016. Конституционные сферы и формы взаимодействия палат парламентов: зарубежный опыт. Наука и образование: хозяйство и экономика; предпринимательство; право и управление, 11 (78): 82-87.

7. Полухин О.Н., Минасян А.А. 2018. Типичные конституционные формы взаимодействия палат парламентов стран Европы. Современное общество и право, 6 (37): 41-45.

8. Стус Н.В., Никонова Л.И., Минасян А.А. 2019. Взаимодействие палат парламентов в странах Азии. Право и государство: теория и практика, 8 (176): 13-15.

9. Minasyan A.A., Markhgeym M.V., Plohih A.N., Lepeshkina O.V., Rasskazov V.L. 2019. Typical constitutional spheres of interaction among parliament chambers in the Asian countries. REVISTA INCLUSIONES. VOLUMEN 6. NÚMEROE SPECIAL-ABRIL/JUNIO: 99-105.

10. Nikonova L.I., Markhgeym M.V., Novikova A.E., Minasyan A.A., Kurova N.N. 2017. Constitutional Spheres and Forms of Interaction among Chamber in Modern Parliaments. Journal of Politics and Law, Vol. 10, 4: 201-206.

11. Dzybova S.G., Markhgeym M.V., Minasyan A.A., Plohih A.N., Stus N.V. 2018. Typical constitutional forms of interaction between the foreign parliament chambers. Revista Amazonia Investiga, Vol. 7, 12: 181-186.

\section{References}

1. Marhgejm M.V. 2018. Vzaimodejstvie kak konstitucionnyj princip [Interaction as a constitutional principle]. Nauka i obrazovanie: hozyajstvo i ekonomika; predprinimatel'stvo; pravo i upravlenie, 1 (92): 54-56.

2. Marhgejm M.V., Bezuglaya A.A. 2020. Konstitucionno-pravovoj opyt vzaimodejstviya bikameral'nyh parlamentov stran SNG v sfere prodovol'stvennoj bezopasnosti [Constitutional and legal experience of interaction of bicameral parliaments of the CIS countries in the field of food security]. Social'no-politicheskie nauki, 10 (5): 43-49.

3. Minasyan A.A. 2017. "Soglasitel'noe" vzaimodejstvie palat Federal'nogo Sobraniya Rossijskoj Federacii ["Conciliatory" interaction of the Chambers of the Federal Assembly of the Russian Federation]. Nauka i obrazovanie: hozyajstvo i ekonomika; predprinimatel'stvo; pravo i upravlenie, 2 (81): 88-91.

4. Minasyan A.A., Nikonova L.I. 2016. Vzaimodejstvie palat zarubezhnyh parlamentov v zakonodatel'noj sfere [Interaction of the Chambers of foreign parliaments in the legislative sphere]. In: Konstitucionalizaciya Rossii: problemy teorii i sovremennoj praktiki. [Constitutionalization of Russia: problems of Theory and Modern Practice]. Ed. Markheim M. V. Belgorod: 86-90.

5. Minasyan A.A., Nikonova L.I. 2017. Komitety i komissii palat zarubezhnyh parlamentov: strukturno-funkcional'naya harakteristika [Committees and commissions of the Chambers of foreign Parliaments: structural and functional characteristics]. In: Pravo i gosudarstvo v sovremennom mire: sostoyanie, problemy, tendencii razvitiya. [Law and the State in the Modern World: State, Problems, Development Trends]. Materials of the IV International Scientific and Theoretical Conference "Maltsev Readings" in memory of the Honored Scientist of the Russian Federation, Corresponding Member of the Russian Academy of Sciences, Doctor of Law, Professor Gennady Maltsev. Belgorod, April 28, 2017. Belgorod: 89-93.

6. Minasyan A.A., Nikonova L.I. 2016. Konstitucionnye sfery i formy vzaimodejstviya palat parlamentov: zarubezhnyj opyt [Constitutional spheres and forms of interaction between the Chambers of Parliaments: foreign experience]. Nauka i obrazovanie: hozyajstvo i ekonomika; predprinimatel'stvo; pravo i upravlenie, 11 (78): 82-87.

7. Poluhin O.N., Minasyan A.A. 2018. Tipichnye konstitucionnye formy vzaimodejstviya palat parlamentov stran Evropy [Typical constitutional forms of interaction between the Chambers of Parliaments of European countries]. Sovremennoe obshchestvo i pravo, 6 (37): 41-45.

8. Stus N.V., Nikonova L.I., Minasyan A.A. 2019. Vzaimodejstvie palat parlamentov v stranah Azii [Interaction of the Chambers of Parliaments in Asia]. Pravo i gosudarstvo: teoriya i praktika, 8 (176): $13-15$. 
9. Minasyan A.A., Markhgeym M.V., Plohih A.N., Lepeshkina O.V., Rasskazov V.L. 2019. Typical constitutional spheres of interaction among parliament chambers in the Asian countries. REVISTA INCLUSIONES. 2019. VOLUMEN 6. NÚMEROE SPECIAL-ABRIL/JUNIO: 99-105.

10. Nikonova L.I., Markhgeym M.V., Novikova A.E., Minasyan A.A., Kurova N.N. 2017. Constitutional Spheres and Forms of Interaction among Chamber in Modern Parliaments. Journal of Politics and Law, Vol. 10, 4: 201-206.

11. Dzybova S.G., Markhgeym M.V., Minasyan A.A., Plohih A.N., Stus N.V. 2018. Typical constitutional forms of interaction between the foreign parliament chambers. Revista Amazonia Investiga, Vol. 7, 12: 181-186.

\section{ИНФОРМАЦИЯ ОБ АВТОРАХ}

Мархгейм Марина Васильевна, профессор, доктор юридических наук, заведующая кафедрой конституционного и международного права юридического института Белгородского государственного национального исследовательского университета, г. Белгород, Россия.

Безуглая Анна Артуровна, кандидат юридических наук, доцент кафедры конституционного и международного права юридического института Белгородского государственного национального исследовательского университета, г. Белгород, Россия

\section{INFORMATION ABOUT THE AUTHORS}

Marina V. Markhgeym, Professor, Doctor of Law, Head of the Department of Constitutional and International Law of the Law Institute, Belgorod State National Research University, Belgorod, Russia.

Anna A. Bezuglya, Candidate of Law, Associate Professor of the Department of Constitutional and International Law of the Law Institute, Belgorod State National Research University, Belgorod, Russia 